Check for updates

Cite this: RSC Adv., 2017, 7, 50287

\title{
Toxicity of graphene oxide to white moss Leucobryum glaucum
}

\author{
Xiaowei Lin, Lingyun Chen, Xin Hu, Shicheng Feng, Liu Huang, Guoping Quan, \\ Xue Wei and Sheng-Tao Yang (iD *
}

Environmental biosafety is the key issue in the healthy development of the graphene industry, but the toxicity of graphene to moss is still unknown to date. Herein, we investigated the influence of graphene oxide (GO) on the growth, chlorophyll content and structure of white moss Leucobryum glaucum. Our results indicated that GO did not alter the fresh weight of L. glaucum, but inhibited the dry weight gain seriously, resulting in higher water-holding rates. GO induced the suppression of chlorophyll contents and up-regulated the chlorophyll a/b ratios, thus might influence the photosynthesis of L. glaucum. GO disturbed the microstructure and ultrastructure of L. glaucum at high concentrations, inducing the destruction of cell wall, the separation of cell wall and membrane, and the formation of micropores on the leave surface. GO led to the decrease of glutathione levels and catalase activities of L. glaucum, suggesting the existence of oxidative stress. Our results collectively suggested that graphene had the potential environmental risk to moss plants, and the release of graphene into the environment should be strictly restricted.

Received 11th September 2017 Accepted 24th October 2017

DOI: 10.1039/c7ra10096e

rsc.li/rsc-advances induced viability loss and oxidative stress following a dose- and size-dependent way. ${ }^{16}$ For white rot fungi, GO led to the weight loss, structural disturbance and decomposition activity decrease after the co-incubation for $14 \mathrm{~d} \cdot{ }^{\mathbf{1 7}}$ For bacteria, GO became more toxic to Escherichia coli and Bacillus subtilis after photolysis. ${ }^{18}$ Upon the pulmonary exposure to mice, GO accumulated in lung and aroused oxidative stress, inflammatory infiltration and fibrosis. ${ }^{19}$ As for plants, GO led to the inhibition of germination, the suppression of root development, and the disturbance of photosynthesis. ${ }^{20}$ During these investigations, more and more evidence indicated that oxidative stress was the toxicological mechanism of graphene materials. ${ }^{21,22}$ Beyond these representative species, the impact of graphene on the lower plants, such as moss and lichen, has not been concerned yet. The lack of such information definitely hinders the full understand of the environmental risks of graphene.

Moss is an important component of the ecological system. ${ }^{2324}$ Moss originates from phycophyta and distributes worldwide from the Arctic tundra to Antarctic glacier. Moss is an important primary producer, in particular for frigid zones. Moss accommodates the nitrogen-fixing bacteria for nitrogen fixation and moss itself holds soluble phosphorus, therefore moss plays crucial roles in geobiochemical cycle of $\mathrm{N}$ and P. Moss could improve the soil quality together with bacteria on its rhizoids. Moss has huge water-holding capacity, thus, is crucial for water balance. Moss also provides accommodation and/or food for many creatures. Moss even helps the growth of plants such as hemlock, Souliea vaginata and Saxifraga. In addition, moss is used for environmental monitoring, due to 
the high sensitivity to pollutants and climate changes. ${ }^{25,26}$ When graphene enters the environment, the direct contact of graphene with moss is unavoidable. ${ }^{27}$ The impact of graphene on moss might lead to serious consequences, so the toxicity of graphene to moss should be investigated to fully understand the environmental risks of graphene. ${ }^{28}$

In this study, we used white moss Leucobryum glaucum as the model plant to investigate the environmental hazards of GO. $L$. glaucum was incubated with GO for $28 \mathrm{~d}$ before toxicity assessments. The fresh and dry weights of L. glaucum were measured to calculate the water-holding rates. The chlorophyll contents were analysed for chlorophyll $\mathrm{a} / \mathrm{b}$ ratio calculation. The plant was sectioned for optical microscope observations and the ultrathin sections were checked under transmission electron microscopy (TEM). The freeze-dried L. glaucum samples were examined by scanning electron microscope (SEM). To elucidate the potential toxicological mechanism, the glutathione (GSH) and catalase (CAT) levels were quantified. The implication to the biosafety and environmental effects of graphene is discussed.

\section{Results and discussion}

\section{Characterization of GO}

GO formed a brown dispersion upon sonication in water. According to the atomic force microscope (AFM) observation, the GO sheets were single-layer dispersed with a height of $0.8 \mathrm{~nm}$. When preparing TEM specimen, GO sheets wrinkled slightly during the drying (Fig. 1a), but most of them were still single-layered. The typical G-band and D-band could be easily distinguished in the Raman spectrum (Fig. 1b), suggesting the $\mathrm{sp}^{2}$ carbon atoms and the abundant defects. Based on X-ray photoelectron spectroscopy (XPS) analysis, there were about 32 at\% of oxygen atoms and 68 at\% of carbon atoms in GO samples. The oxygen containing groups were also indicated by

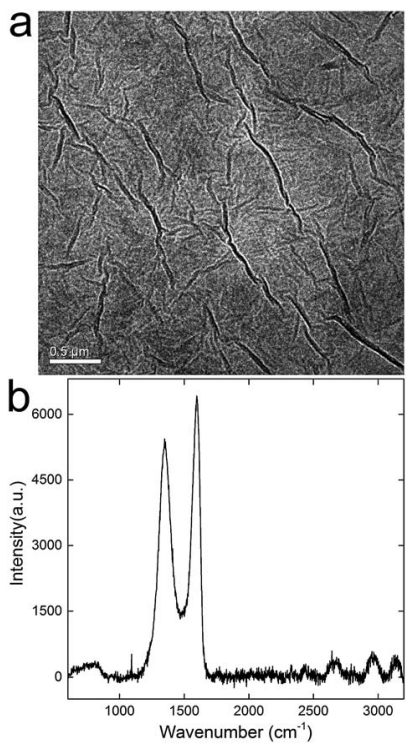

Fig. 1 TEM image (a) and Raman spectrum (b) of GO. the IR spectrum, where $-\mathrm{OH} /-\mathrm{COOH}$ groups were reflected by the broad band at $3400 \mathrm{~cm}^{-1}$ and $\mathrm{C}=\mathrm{O}$ bonds were indicated by the peak at $1720 \mathrm{~cm}^{-1}$. The characterization data collectively suggested that the GO sample of high purity was suitable for the following toxicological experiments. ${ }^{16,17}$

\section{Growth and water-holding rate}

As described in the Introduction, moss is an important component of the environment and also useful in environmental monitoring. ${ }^{23,24}$ However, the hazards of carbon nanomaterials to moss have not been investigated yet, leaving this area as virgin land. Some efforts were only paid to the synthesis of carbon nanomaterials from moss skeleton, such as carbon nanosheets and carbon nanotubes. ${ }^{29,30}$ Therefore, it is necessary to evaluate the potential toxicity of graphene to moss. ${ }^{31}$ Generally, GO had minor influence on the fresh weight of L. glaucum (Fig. 2a). A slight decrease was found at the GO concentration of $0.4 \mathrm{mg} \mathrm{mL} \mathrm{m}^{-1}$ and an increase occurred at $1.0 \mathrm{mg} \mathrm{mL} \mathrm{me}^{-1}$. The increase at $1.0 \mathrm{mg} \mathrm{mL}{ }^{-1}$ might be associated with the aggregation of GO at high concentrations that reduced the bioavailability of GO to L. glaucum. Similarly, Wang et al. observed the inverse dose-effect of carbon nanomaterials to soybean and attributed this to the agglomeration of carbon nanomaterials at high concentrations. ${ }^{32}$ However, the dry weights of $L$. glaucum significantly decreased at all GO concentrations (Fig. 2b). No apparent dose-effect was presented in the concentration range of 0.04-4 $\mathrm{mg} \mathrm{mL}^{-1}$. The loss of fresh weight suggested that the photosynthesis of L. glaucum might be down-regulated. The influence of weight gain by graphene nanomaterials were widely observed in the studies using higher plants as the model. ${ }^{33-35}$ For examples, sulfonated graphene decreased the biomass of maize seedlings at $100 \mathrm{mg} \mathrm{L}^{-1}$ and higher concentrations. ${ }^{33}$ Zhang et al. found that graphene inhibited the weight increase

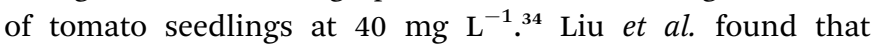

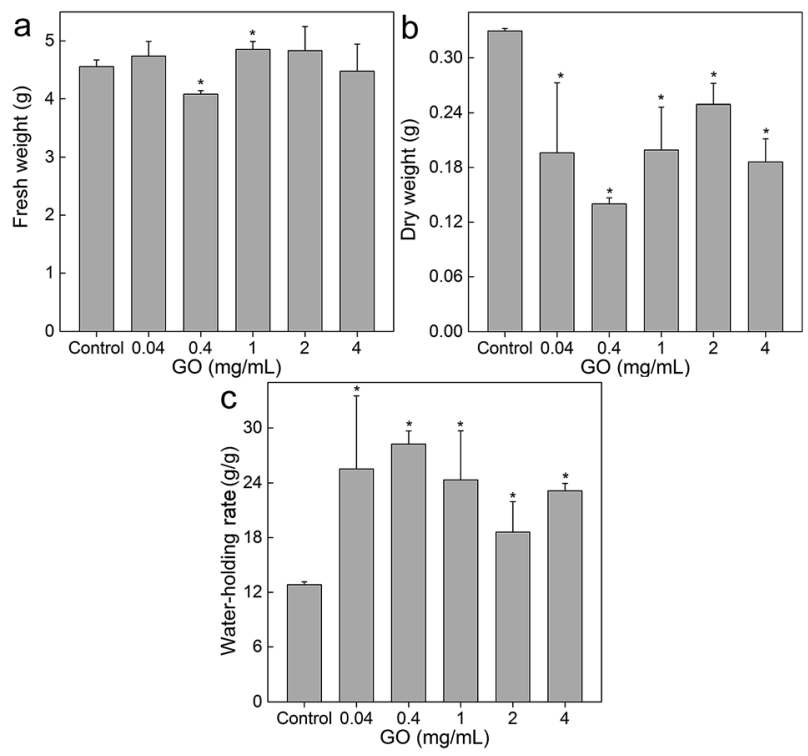

Fig. 2 Fresh weight (a), dry weight (b) and water-holding rate (c) of $L$. glaucum after the exposure to $\mathrm{GO}(n=4)$. 
graphene stimulated the weight gains of both root and shoot of rice at $5 \mathrm{mg} \mathrm{L}^{-1}$ and then inhibited the weight gains at $50 \mathrm{mg} \mathrm{L}^{-1}$ and higher. ${ }^{35}$

The unchanged fresh weights and decreased dry weights could be converted into the large increases of water-holding rates. As shown in Fig. 2c, the water-holding rate of L. glaucum was nearly doubled upon the exposure to GO of concentrations of $0.04 \mathrm{mg} \mathrm{mL}^{-1}$ and higher. The increased waterholding rate suggested that the skeleton of L. glaucum was not compressed and could still hold large quantity of water. To this regard, the toxicity to L. glaucum did not affect the capacity of maintaining water balance in short-term.

\section{Chlorophyll content}

The loss of dry weight implied that the photosynthesis of $L$. glaucum was suppressed. Therefore, we quantified the chlorophyll contents of $L$. glaucum samples to verify this. As indicated in Fig. 3a, GO did not influence the chlorophyll a much. The only significant increase was observed at GO concentration of $2 \mathrm{mg} \mathrm{mL}{ }^{-1}$. More changes were found in chlorophyll b, where significant decreases were observed at GO concentrations from 0.04 to $4 \mathrm{mg} \mathrm{mL}^{-1}$ (Fig. 3b). The chlorophyll a/b ratios increased significantly at all GO concentrations (Fig. 3c). The increase of chlorophyll $\mathrm{a} / \mathrm{b}$ ratio meant that the light utility of blue region was suppressed. For L. glaucum, the utilization of blue light was crucial, because moss preferred weak light. The decreased chlorophyll b suggested that the photosynthesis of L. glaucum was inhibited, which explained the decreased dry weight.

By reviewing the literature results, it could be concluded that the influence of carbon nanomaterials on chlorophyll contents depended on both the properties of materials and also the species of plants. Previously, we found that hydroxylated fullerene stimulated the chlorophyll contents in wheat. ${ }^{36}$ On the other hand, GO decreased the chlorophyll contents of wheat at

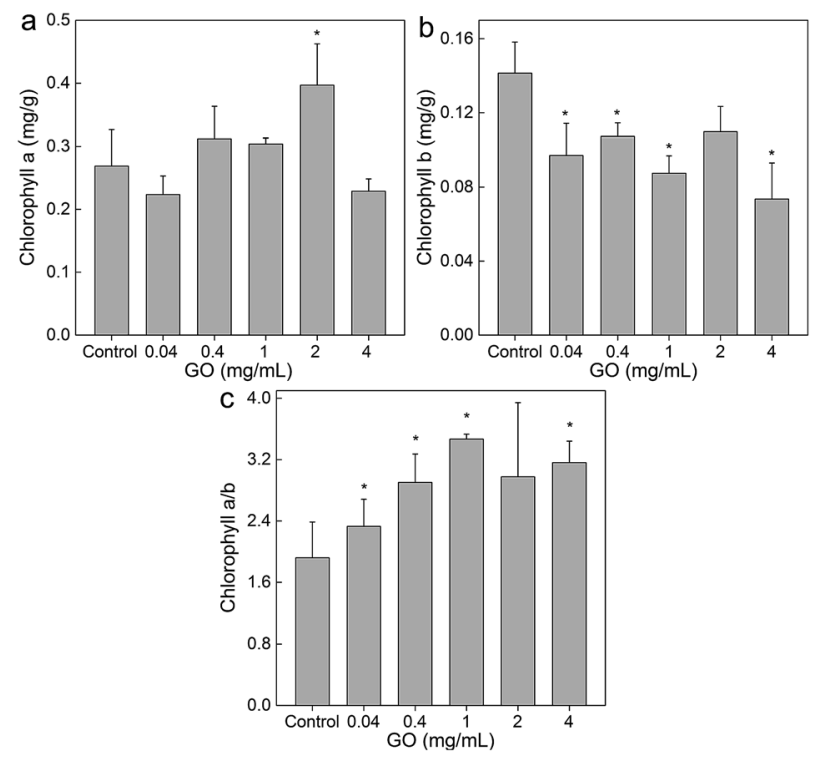

Fig. 3 Influence of GO on the chlorophyll content of L. glaucum ( $n=$ 4). (a) Chlorophyll a; (b) chlorophyll b; (c) chlorophyll a/b ratio.
$0.5 \mathrm{mg} \mathrm{mL}^{-1}$ after $30 \mathrm{~d}$ exposure. ${ }^{37} \mathrm{Hu}$ et al. reported that graphene, hydrated graphene ribbon and GO could decrease the chlorophyll a contents and up-regulated the chlorophyll a/ b ratios. ${ }^{38}$ Reduced GO was found to down-regulate the chlorophyll contents and $\mathrm{a} / \mathrm{b}$ ratios of another lower plant green alga Scenedesmus obliquus..$^{39}$ In our study, we observed the decreases of chlorophyll b contents and up-regulated chlorophyll a/ b ratios of L. glaucum. Our results were different to aforementioned examples, suggesting the unique characteristics of moss.

\section{Structure and ultrastructure}

GO toxicity was reflected by the changes of structure and ultrastructure. First, we sectioned the L. glaucum samples and stained them by safranin and fast green for optical microscopy. As shown in Fig. 4, the control group had nearly intact structure. The single layer of chlorophyllose cells were well aligned and embedded in the empty hyaline cells. ${ }^{23}$ The adjoining walls of the hyaline cells were easily recognized. Upon the exposure to GO, the major change was the destruction of adjoining walls. The phenomenon was particularly serious at GO concentration of $2 \mathrm{mg} \mathrm{mL}^{-1}$. In the stem of the L. glaucum plant, the breaking of cell walls was more obvious comparing to that in the leaves. The morphological changes indicated that GO was toxic to $L$. glaucum.

The L. glaucum samples were checked under TEM to verify the ultrastructural changes. The control group had normal structures of chlorophyllose cell (Fig. 5a). The cell membrane and the cell wall were tightly attached and both were intact. The chloroplast was clearly presented. The ultrastructure kept nearly unchanged except the vesicles in chloroplasts at GO concentration of $0.04 \mathrm{mg} \mathrm{mL}^{-1}$ (Fig. 5b). Serious shrink of cell

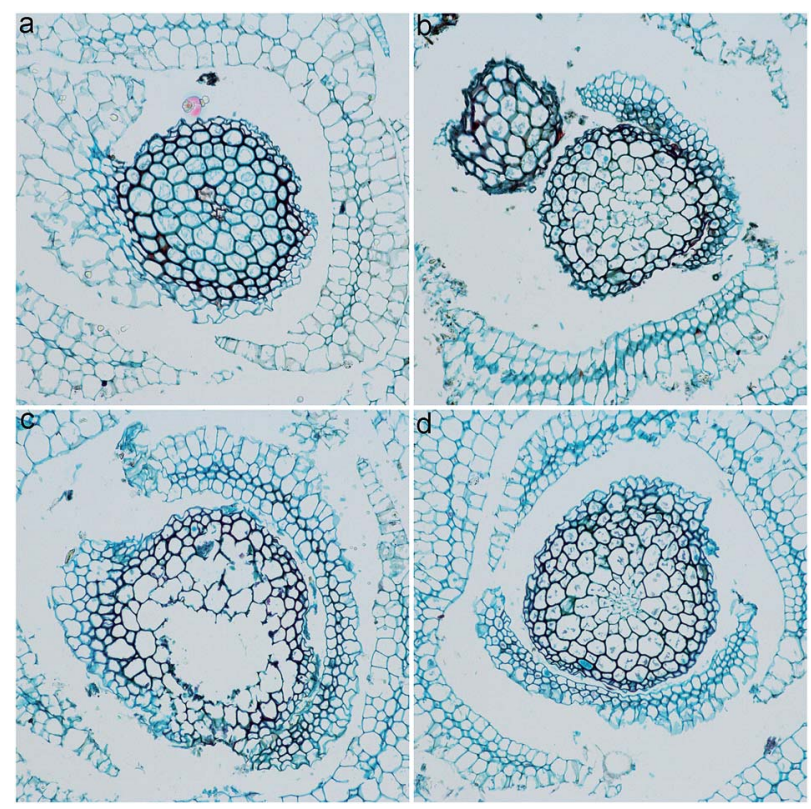

Fig. 4 Structural changes of L. glaucum upon the exposure to GO $(200 \times)$. (a) Control group; (b) L. glaucum exposed to GO at $0.1 \mathrm{mg}$ $\mathrm{mL}^{-1}$; (c) L. glaucum exposed to GO at $2 \mathrm{mg} \mathrm{mL}^{-1}$; (d) L. glaucum exposed to $\mathrm{GO}$ at $4 \mathrm{mg} \mathrm{mL}^{-1}$. 


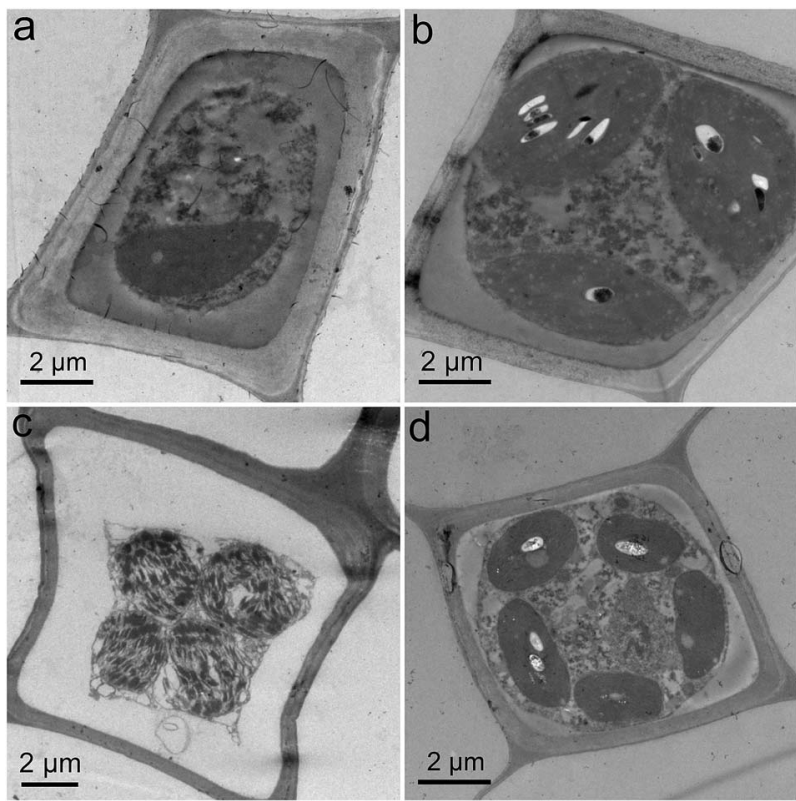

Fig. 5 Ultrastructural changes of L. glaucum upon the exposure to GO. (a) Control group; (b) L. glaucum exposed to $\mathrm{GO}$ at $0.04 \mathrm{mg} \mathrm{mL}^{-1}$; (c) L. glaucum exposed to $\mathrm{GO}$ at $1 \mathrm{mg} \mathrm{mL}^{-1}$; (d) L. glaucum exposed to $\mathrm{GO}$ at $4 \mathrm{mg} \mathrm{mL}^{-1}$.

plasma was observed at $1.0 \mathrm{mg} \mathrm{mL}^{-1}$ of GO (Fig. 5c). The cell wall and membrane detached due to the shrink. The nucleus was squeezed by the chloroplasts to a very small size and the thylakoids had higher contrast. At $4.0 \mathrm{mg} \mathrm{mL}{ }^{-1}$, the ultrastructural changes seemed to be relieved, although the detachment of wall-membrane and the vesicles in chloroplasts were still observed (Fig. 5d). No GO was observed in the L. glaucum cells at all GO concentrations, suggesting that GO could hardly penetrate the cell wall. In the contrast, iron nanoparticles penetrated in the leave cells of another moss species [Physcomitrella patens (Hedw.) Bruch \& Schimp] after the exposure as the mineral solution. ${ }^{40}$ The iron nanoparticles $(20-80 \mathrm{~nm})$ were smaller in size than GO (several micrometres), so the iron nanoparticles penetrated the cells easier. According to the literature, GO could be absorbed by the root of higher plants, such as Arabidopsis thaliana and tomato. ${ }^{34,41}$ Moss lacked the real root and the rhizoid worked as the anchor. Therefore, the penetration of GO into moss plant did not occurred during our experiment.

SEM was adopted to investigate the surficial morphology of L. glaucum samples. It could be seen that the surface of control group was flat with a few wrinkles and very a few of small particles (Fig. 6a). No obvious change was found at GO concentration of $0.04 \mathrm{mg} \mathrm{mL}^{-1}$ (Fig. 6b). The heights of wrinkles became a little larger at GO concentrations of 1 and $4 \mathrm{mg}$ $\mathrm{mL}^{-1}$ (Fig. 6c and d). No graphene sheets were found on the surface of $L$. glaucum, suggesting the washing was very efficient to remove the attached GO. Interestingly, some micropores were found in the $4 \mathrm{mg} \mathrm{mL}^{-1}$ group with the diameters of 10-20 $\mu \mathrm{m}$ (Fig. 6e and f). The SEM results suggested that GO had slight influence on the surficial morphology of L. glaucum and the major structures were retained.
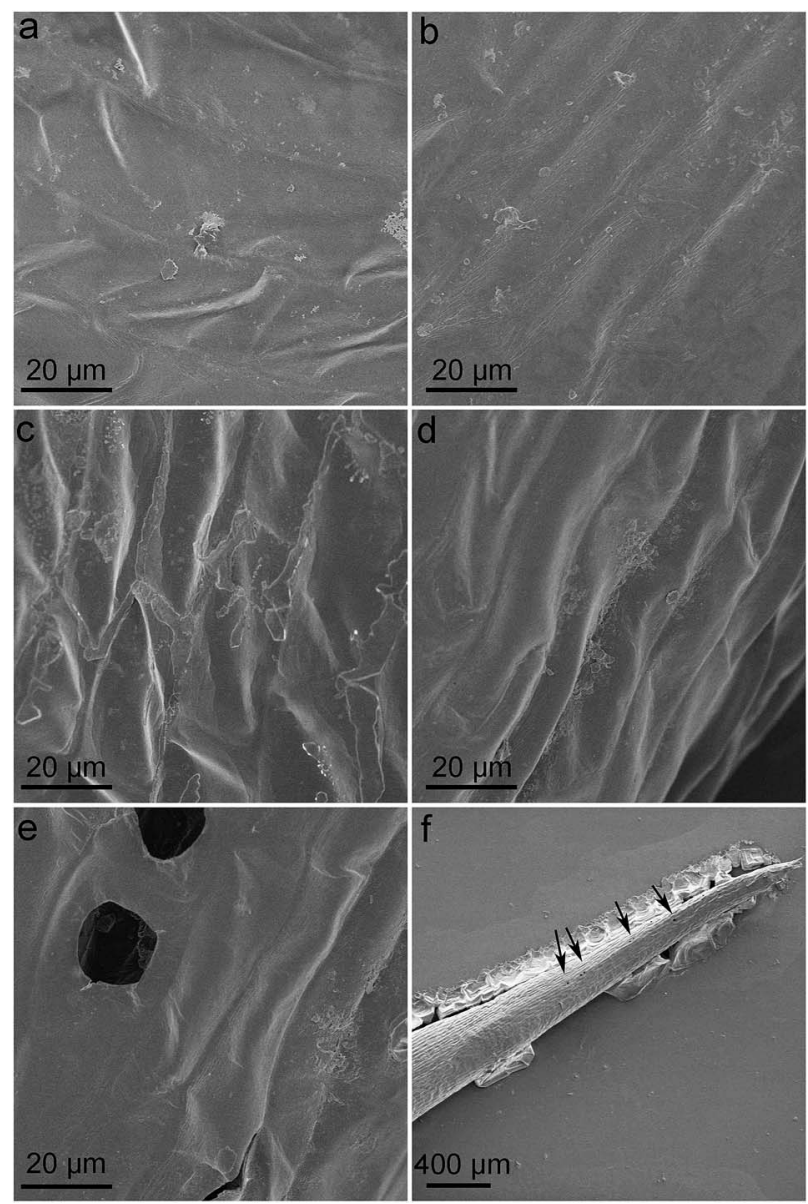

Fig. 6 Surficial morphology of L. glaucum after the exposure to GO. (a) Control group; (b) L. glaucum exposed to $\mathrm{GO}$ at $0.04 \mathrm{mg} \mathrm{mL}^{-1}$; (c) L. glaucum exposed to $\mathrm{GO}$ at $1 \mathrm{mg} \mathrm{mL}^{-1}$; (d-f) L. glaucum exposed to $\mathrm{GO}$ at $4 \mathrm{mg} \mathrm{mL}^{-1}$.

\section{Oxidative stress}

Oxidative stress is a widely proposed toxicological mechanism of nanomaterials..$^{42}$ The literature studies have suggested that graphene induced oxidative damage to plants..$^{20-22,33,38}$ Herein, we measured the GSH and CAT levels to reflect the oxidative stress level of $L$. glaucum. As shown in Fig. 7a, the GSH level showed a dose-dependent decrease upon the exposure to GO. The decreases became significant at GO concentrations of $1 \mathrm{mg}$ $\mathrm{mL}^{-1}$ and higher. GSH was the main species to quench reactive oxygen species (ROS) in cells. The depletion of GSH would lead to the oxidative damage of $L$. glaucum. The CAT level slightly increased at $1 \mathrm{mg} \mathrm{mL}^{-1}$ of GO and then decreased (Fig. 7b). CAT was the enzyme to decompose intracellular $\mathrm{H}_{2} \mathrm{O}_{2}$. The upregulation of CAT at low $\mathrm{GO}$ concentrations could be regarded as the stress reaction of L. glaucum. At high GO concentrations, the CAT levels decreased, which indicated the serious oxidative damage. In another study on moss, the iron nanoparticles increased the ROS levels of $P$. patens at $72 \mathrm{~h}$ post foliar exposure. ${ }^{43}$ For future studies, further toxicological mechanism investigations at molecular levels should be performed. ${ }^{44}$ Overall, the oxidative stress occurred in L. glaucum after the 

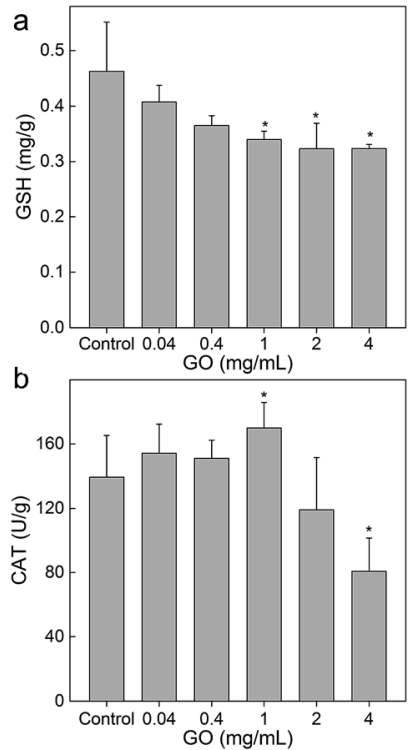

Fig. 7 Influence of GO on the GSH (a) and CAT (b) levels of L. glaucum $(n=4)$.

exposure to GO and the oxidative damage was one of the toxicological pathways of GO to L. glaucum.

\section{Conclusions}

In summary, GO induced obvious toxicity to white moss $L$. glaucum, where the oxidative stress was considered as the possible toxicological mechanism. GO induced the weight loss, water-holding rate increase, alteration of chlorophyll contents, and structural change to L. glaucum. The decreased GSH levels and the changed CAT levels collectively indicated the existence of oxidative stress during the exposure to GO. The toxicity results suggested that the release of graphene materials into the environment might induce potential hazards to moss and consequently influence the $\mathrm{C} / \mathrm{N} / \mathrm{P}$ cycles, the water balance and the living of other organisms in particular at high concentrations during the environmental accidents. On the other hand, the sensitivity of moss might be utilized for monitoring the environmental impact of nanomaterials. In addition, the tolerance of moss to GO at extremely high concentration of $4.0 \mathrm{mg} \mathrm{mL} \mathrm{m}^{-1}$ also provided a potential environmental restoration approach in future. It is hoped that our results would benefit the ongoing environmental safety evaluation of graphene materials and stimulate more interest of using moss as model plant for nanoimpact investigations.

\section{Experimental}

\section{Preparation of GO}

GO was prepared by modified Hummers' method. ${ }^{44}$ Briefly, graphite $(3.0 \mathrm{~g})$ was pre-oxidized with $\mathrm{P}_{2} \mathrm{O}_{5}(2.5 \mathrm{~g})$ and $\mathrm{K}_{2} \mathrm{~S}_{2} \mathrm{O}_{8}$ $(2.5 \mathrm{~g})$ in $\mathrm{H}_{2} \mathrm{SO}_{4}(12 \mathrm{~mL})$ at $80{ }^{\circ} \mathrm{C}$ for $4.5 \mathrm{~h}$. After cooling to room temperature, the suspension was diluted with deionized water, filtered, washed, and dried under vacuum. The residue in $\mathrm{H}_{2} \mathrm{SO}_{4}$
$(120 \mathrm{~mL})$ was oxidized by $\mathrm{KMnO}_{4}(15 \mathrm{~g})$ at $35{ }^{\circ} \mathrm{C}$ for $2 \mathrm{~h}$ (solid $\mathrm{KMnO}_{4}$ should be added very slowly under stirring). Then, the mixture was added into $250 \mathrm{~mL}$ of deionized water and stirred for another $2 \mathrm{~h}$. To the mixture, $500 \mathrm{~mL}$ of deionized water and $20 \mathrm{~mL}$ of $\mathrm{H}_{2} \mathrm{O}_{2}(30 \% \mathrm{v} / \mathrm{v})$ were added. After filtration, the residue was washed by $\mathrm{HCl}$ aqueous solution $(10 \% \mathrm{v} / \mathrm{v})$ and dialyzed against deionized water for $7 \mathrm{~d}$. GO was characterized by IR (Avatar 370, Thermo Nicolet, USA), XPS (Kratos, UK), TEM (JEM200CX, JEOL, Japan), AFM (SPM-9600, Shimadzu, Japan) and Raman spectroscopy (inVia, Renishaw, UK).

\section{Exposure of GO to L. glaucum}

The L. glaucum was purchased from Unique Landscape Co., China, who collected the L. glaucum from Wuyi Mountain. L. glaucum was placed on filter paper in transparent plastic box and watered to keep the container wet. The moss was cultivated for $48 \mathrm{~h}$ before exposure (a day/night cycle of $12 \mathrm{~h} / 12 \mathrm{~h}$, temperatures of $25 / 25{ }^{\circ} \mathrm{C}$, illumination of $24000 \mathrm{~lx}$ during the day cycle, and $80 \%$ relative humidity). Then, GO was dispersed in modified Hoagland nutrient solution and exposed to $L$. glaucum at concentrations of $0.04-4 \mathrm{mg} \mathrm{mL}^{-1} \cdot{ }^{33}$ Moss cultivated without GO was taken as the control group. Modified Hoagland nutrient solution was added daily to maintain the total volume of solution unchanged during the observation period. The $L$. glaucum samples were collected at $28 \mathrm{~d}$ post exposure for toxicity assays.

\section{Toxicity assessments}

L. glaucum samples were washed with deionized water to removal all attached GO and then soaked in deionized water for 24 h. L. glaucum samples were placed on a screen mesh to remove the extra water before fresh weight $\left(m_{\mathrm{f}}\right)$ measurements. After weighting, the samples were dried at $65^{\circ} \mathrm{C}$ for $48 \mathrm{~h}$ for dry weight $\left(m_{\mathrm{d}}\right)$ measurements. The water-holding rate $(R)$ was calculated following eqn (1).

$$
R=\frac{m_{\mathrm{f}}-m_{\mathrm{d}}}{m_{\mathrm{d}}} \times 100 \%
$$

For chlorophyll content measurements, L. glaucum samples were washed with ice-cold phosphate buffered solution and the water was sucked by filter paper. Then, $0.1 \mathrm{~g}$ of each sample was mixed with $5 \mathrm{~mL} \mathrm{95 \%} \mathrm{alcohol} \mathrm{and} \mathrm{homogenized} \mathrm{in} \mathrm{an} \mathrm{ice} \mathrm{bath.}$ The mixture was filtered and the volume of the filtrate was adjusted to $5.00 \mathrm{~mL}$. The absorbance at $665 \mathrm{~nm}$ and $649 \mathrm{~nm}$ was recorded for chlorophyll content calculation following eqn (2) and (3).

$$
\begin{aligned}
& \text { Chlorophyll } \mathrm{a}=\frac{\left(13.95 \times A_{665 \mathrm{~nm}}-6.88 \times A_{649 \mathrm{~nm}}\right) \times 5}{0.1 \times 1000} \\
& \text { Chlorophyll } \mathrm{b}=\frac{\left(24.96 \times A_{649 \mathrm{~nm}}-7.32 \times A_{665 \mathrm{~nm}}\right) \times 5}{0.1 \times 1000}
\end{aligned}
$$

For structural change observations, the fresh L. glaucum samples were fixed with formaldehyde-acetate-alcohol solution. The samples were embedded in paraffin, sectioned with 10 
$\mu \mathrm{m}$ thicknesses, and stained with safranin and fast green. Images of the L. glaucum paraffin sections were recorded under a microscope (CAB-30PC, Cabontek Co., Chengdu, China). Another set of L. glaucum samples were fixed with $3 \%$ glutaraldehyde, post-fixed in $1 \%$ osmium tetroxide, dehydrated in a graded alcohol series, and embedded in epoxy resin. Sections were cut with an ultramicrotome and post-stained with uranyl acetate and lead citrate for TEM examination. The third set of samples were lyophilized and coated with gold for $5 \mathrm{~s}$ using a sputter coater (JFC 1600, JEOL, Japan), and observed with a SEM (JSM-7500, JEOL, Japan).

For oxidative stress assays, all kits were obtained from the Nanjing Jiancheng Bioengineering Institute, Nanjing, China. $L$. glaucum samples were homogenized in ice-cold water $(0.1 \mathrm{~g}$ tissue/5 $\mathrm{mL}$ water). The samples were centrifuged at $8000 \mathrm{rpm}$ for $3 \mathrm{~min}$ to remove the residues. The protein concentration was determined by staining with Coomassie brilliant blue. The GSH and CAT levels were analyzed following the manufacturer's instructions using an UV-vis spectrophotometer (UV-1800, Mapada, China). The protocols could be found at http:// elder.njjcbio.com/index_en.php.

\section{Statistical analysis}

All data were expressed as the mean of four individual samples with standard deviation (mean $\pm \mathrm{SD}$ ). Significance was calculated by using Student's $t$-test, where $p<0.05$ was considered as statistically significant.

\section{Conflicts of interest}

There are no conflicts to declare.

\section{Acknowledgements}

We acknowledge financial support from the China Natural Science Foundation (No. 21777132 and 201307101), the Topnotch Young Talents Program of China, and the Fundamental Research Funds for the Central Universities, Southwest Minzu University (No. 2016NZDFH01).

\section{Notes and references}

1 A. K. Geim, Science, 2009, 5934, 1530-1534.

2 K. S. Novoselov, V. I. Falko, L. Colombo, P. R. Gellert, M. G. Schwab and K. Kim, Nature, 2012, 490, 192-200.

3 F. Banhart, J. Kotakoski and A. V. Krasheninnikov, ACS Nano, 2011, 5, 26-41.

4 W. Y. Fu, L. Jiang, E. P. van Geest, L. M. C. Lima and G. F. Schneider, Adv. Mater., 2017, 29, 1603610.

5 Y. F. Dong, Z. S. Wu, W. C. Ren, H. M. Cheng and X. Bao, Sci. Bull., 2017, 62, 724-740.

6 A. Ambrosi, C. K. Chua, N. M. Latiff, A. H. Loo, C. H. A. Wong, A. Y. S. Eng, A. Bonanni and M. Pumera, Chem. Soc. Rev., 2016, 45, 2458-2493.

7 C. Cheng, S. Li, A. Thomas, N. A. Kotov and R. Haag, Chem. Rev., 2017, 117, 1826-1914.
8 J. Xu, H. Lv, S.-T. Yang and J. Luo, Rev. Inorg. Chem., 2013, 33, 139-160.

9 A. K. Sundramoorthy and S. Gunasekaran, TrAC, Trends Anal. Chem., 2014, 60, 36-53.

10 R. Wu, B. Yu, X. Liu, H. Li, W. Wang, L. Chen, Y. Bai, Z. Ming and S.-T. Yang, Appl. Surf. Sci., 2016, 362, 56-62.

11 L. Zhao, B. Yu, F. Xue, J. Xie, X. Zhang, R. Wu, R. Wang, Z. Hu, S.-T. Yang and J. Luo, J. Hazard. Mater., 2015, 286, 449-456.

12 S. Gurunathan and J. H. Kim, Int. J. Nanomed., 2016, 11, 1927-1945.

13 A. Montagner, S. Bosi, E. Tenori, M. Bidussi, A. A. Alshatwi, M. Tretiach, M. Prato and Z. Syrgiannis, 2D Mater., 2017, 4, 012001.

14 Y. Liu, Y. L. Zhao, B. Y. Sun and C. Y. Chen, Acc. Chem. Res., 2013, 46, 702-713.

15 X. Hu and Q. Zhou, Chem. Rev., 2013, 113, 3815-3835.

16 Y. Chang, S.-T. Yang, J.-H. Liu, E. Dong, Y. Wang, A. Cao, Y. Liu and H. Wang, Toxicol. Lett., 2011, 200, 201-210.

17 J. Xie, Z. Ming, H. Li, H. Yang, B. Yu, R. Wu, X. Liu, Y. Bai and S.-T. Yang, Chemosphere, 2016, 151, 324-331.

18 W. C. Hou, P. Lee, Y. Chou and Y. Wang, Environ. Sci.: Nano, 2017, 4, 647-657.

19 B. Li, J. Yang, Q. Huang, Y. Zhang, C. Peng, Y. Zhang, Y. He, J. Shi, W. Li, J. Hu and C. Fan, NPG Asia Mater., 2013, 5, 44.

20 N. A. Anjum, N. Singh, M. K. Singh, I. Sayeed, A. C. Duarte, E. Pereira and I. Ahmad, Sci. Total Environ., 2014, 472, 834-841.

21 L. Kovbasyuk and A. Mokhir, in Graphene oxide: Fundamentals and Applications, ed. A. M. Dimiev and S. Eigler, John Wiley \& Sons Inc., Hoboken, 2016, vol. 11, p. 368.

22 H. Pieper, S. Chercheja, S. Eigler, C. E. Halbig, M. R. Filipovic and A. Mokhir, Angew. Chem., Int. Ed., 2016, 55, 405-407.

23 W. H. Burrell, Bryologist, 1907, 10, 107-111.

24 M. R. Turetsky, Bryologist, 2003, 106, 395-409.

25 J. A. Fernandez, M. T. Boquete, A. Carballeira and J. R. Aboal, Sci. Total Environ., 2015, 517, 132-150.

26 H. Harmens, L. Foan, V. Simon and G. Mills, Environ. Pollut., 2013, 173, 245-254.

27 J. Zhao, Z. Y. Wang, J. C. White and B. S. Xing, Environ. Sci. Technol., 2014, 48, 9995-10009.

28 E. L. K. Chng and M. Pumera, $R S C$ Adv., 2014, 5, 3074-3080. 29 J. Ding, H. Wang, Z. Li, A. Kohandehghan, K. Cui, Z. Xu, B. Zahiri, X. Tan, E. M. Lotfabad, B. C. Olsen and D. Mitlin, ACS Nano, 2013, 7, 11004-11015.

30 D. V. Onishchenko, Surf. Eng. Appl. Electrochem., 2013, 49, 445-449.

31 C. M. Park, K. H. Chu, J. Heo, N. Her, M. Jang, A. Son and Y. Yoon, J. Hazard. Mater., 2016, 309, 133-150.

32 Y. Wang, C. H. Chang, Z. Ji, D. C. Bouchard, R. M. Nisbet, J. P. Schimel, J. L. Gardea-Torresdey and P. A. Holden, ACS Nano, 2017, 11, 5753-5765.

33 W. Ren, H. Chang and Y. Teng, Sci. Total Environ., 2016, 572, 926-934.

34 M. Zhang, B. Gao, J. Chen and Y. Li, J. Nanopart. Res., 2015, 17, 1-8. 
35 S. Liu, H. Wei, Z. Li, S. Li, H. Yan, Y. He and Z. Tian, J. Nanosci. Nanotechnol., 2015, 15, 2695-2701.

36 C. Wang, H. Zhang, L. Ruan, L. Chen, H. Li, X.-L. Chang, X. Zhang and S.-T. Yang, Environ. Sci.: Nano, 2016, 3, 799805.

37 P. Zhang, R. Zhang, X. Fang, T. Song, X. Cai, H. Liu and S. Du, J. Hazard. Mater., 2016, 317, 543-551.

38 X. Hu and Q. Zhou, Sci. Rep., 2014, 4, 3782.

39 S. Du, P. Zhang, R. Zhang, Q. Lu, L. Liu, X. Bao and H. Liu, Chemosphere, 2016, 164, 499-507.
40 L. Canivet, P. Dubot and F.-O. Denayer, J. Bryolog., 2014, 36(2), 104-109.

41 S. Q. Zhao, Q. Q. Wang, Y. L. Zhao, Q. Rui and D. Y. Wang, Environ. Toxicol. Pharmacol., 2015, 39, 145-156.

42 L. Yan, Z. Gu and Y. Zhao, Chem.-Asian J., 2013, 8, 23422353.

43 L. Canivet, P. Dubot, G. Garçon and F.-O. Denayer, Ecotoxicol. Environ. Saf., 2015, 113, 499-505.

44 Y. Bai, Z. Ming, Y. Cao, S. Feng, H. Yang, L. Chen and S.-T. Yang, Colloids Surf., B, 2017, 154, 96-103. 